\title{
暴露 $\{001\}$ 面 $\mathrm{TiO}_{2}$ 纳米片分等级花状结构的制备 及其光催化活性
}

\author{
向全军，余家国* \\ 武汉理工大学材料复合新技术国家重点实验室, 湖北武汉 430070
}

\begin{abstract}
摘要: 以钛酸盐纳米管为前驱体, 在 $\mathrm{HF}-\mathrm{H}_{2} \mathrm{O}-\mathrm{C}_{2} \mathrm{H}_{5} \mathrm{OH}$ 的混合溶液中, 采用一种简单的醇热方法合成了具有 $87 \%$ 暴露 $\{001\}$ 面 的 $\mathrm{TiO}_{2}$ 纳米片自组装形成的分等级花状 $\mathrm{TiO}_{2}$ 超结构. 运用 $\mathrm{X}$ 射线衍射、扫描电镜、透射电镜和 $\mathrm{N}_{2}$ 吸附-脱附等方法对样品 进行了表征, 并在紫外光照射下于空气和溶液中分别考察了其光催化降解丙酮和甲基橙反应活性. 结果表明, 这种分等级花状 结构 $\mathrm{TiO}_{2}$ 的光催化活性比商业 P25 和在纯水中制备得到的片状锐钛矿 $\mathrm{TiO}_{2}$ 的光活性高得多. 这主要是由于该样品具有分等 级的多孔结构, 暴露的 $\{001\}$ 晶面和增强的光吸收能力. 这种分等级花状 $\mathrm{TiO}_{2}$ 超结构在太阳能电池、光催化产氢、光电子器件、 传感器和催化方面也具有巨大的应用前景.
\end{abstract}

关键词: 二氧化钛; 纳米片; $\{001\}$ 晶面; 分等级花状二氧化钛超结构; 光催化活性; 丙酮; 甲基橙

中图分类号: 0643 文献标识码: A

收稿日期: 2010-10-15. 接受日期: 2010-11-13.

*通讯联系人. Tel: (027) 87871029; Fax: (027) 87879468; E-mail: jiaguoyu@yahoo.com

基金来源：国家自然科学基金 (50625208，20773097，20877061); 国家重点基础研究发展计划 (973 计划, 2007CB613302, 2009CB939704); 中央高校基本科研业务费专项资金(2010-YB-01).

本文的英文电子版(国际版)由Elsevier出版社在ScienceDirect上出版(http://www.sciencedirect.com/science/journal/18722067).

\section{Photocatalytic Activity of Hierarchical Flower-Like $\mathrm{TiO}_{2}$ Superstructures with Dominant \{001\} Facets}

\author{
XIANG Quanjun, YU Jiaguo* \\ State Key Laboratory of Advanced Technology for Material Synthesis and Processing, \\ Wuhan University of Technology, Wuhan 430070, Hubei, China
}

\begin{abstract}
The fabrication of well defined hierarchical structures of anatase $\mathrm{TiO}_{2}$ with a high percentage of reactive facets is of great importance and challenging. Hierarchically flower-like $\mathrm{TiO}_{2}$ superstructures (HFTS) self-assembled from anatase $\mathrm{TiO}_{2}$ nanosheets with exposed $\{001\}$ facets (up to $87 \%$ ) were synthesized by a simple alcohothermal strategy in a $\mathrm{HF}-\mathrm{H}_{2} \mathrm{O}-\mathrm{C}_{2} \mathrm{H}_{5} \mathrm{OH}$ mixed solution using titanate nanotubes as precursor. The samples were characterized by X-ray diffraction, scanning electron microscopy, transmission electron microscopy, and $\mathrm{N}_{2}$ adsorption-desorption isotherms. The photocatalytic activity was evaluated by the photocatalytic oxidation decomposition of acetone in air and methyl orange in aqueous solution under UV illumination. The photocatalytic activity of HFTS was much higher than that of commercial Degussa P25 and tabular-shaped anatase $\mathrm{TiO}_{2}$ obtained using pure water as the synthesis medium. The enhancement in photocatalytic activity was related to several factors, including the hierarchically porous structure, exposed $\{001\}$ facets, and increased light harvesting ability. The HFTS was also of interest for use in solar cells, photocatalytic $\mathrm{H}_{2}$ production, optoelectronic devices, sensors, and catalysis.

Key words: titanium dioxide; $\{001\}$ facet; hierarchical flower-like titanium dioxide superstructure; photocatalytic activity; acetone; methyl orange
\end{abstract}

Received 15 October 2010. Accepted 13 November 2010.

*Corresponding author.Tel: +86-27-87871029; Fax:+86-27-87879468; E-mail: jiaguoyu@yahoo.com

This work was supported by the National Natural Science Foundation of China (50625208, 20773097, and 20877061), the National Basic 
Research Program of China (973 Program, 2007CB613302 and 2009CB939704), and Fundamental Research Funds for the Central Universities (2010-YB-01).

English edition available online at Elsevier ScienceDirect (http://www.sciencedirect.com/science/journal/18722067).

Anatase titanium dioxide $\left(\mathrm{TiO}_{2}\right)$ is of great importance due to its increasing applications in photocatalysis, photosplitting of water, solar energy conversion, photochromic devices, and sensors [1-8]. It has been demonstrated that these photocatalytic/photovoltaic properties of anatase $\mathrm{TiO}_{2}$ are strongly dependent on shape, size, and especially the exposed facets $[9,10]$. Theoretical and experimental studies indicate that the (001) surface of anatase $\mathrm{TiO}_{2}$ is much more reactive than the thermodynamically more stable (101) surface [11-13]. Unfortunately, most reported anatase crystals have their surfaces dominated by the less reactive $\{101\}$ facets [14]. This is because the average surface energy for the $\{001\}$ facets of anatase $\mathrm{TiO}_{2}\left(0.90 \mathrm{~J} / \mathrm{m}^{2}\right)$ is two times higher than that of the $\{101\}$ facets $\left(0.44 \mathrm{~J} / \mathrm{m}^{2}\right)$.

Pioneering work by Yang et al. [11] demonstrated the preparation of anatase $\mathrm{TiO}_{2}$ crystals with exposed $\{001\}$ facets through the use of hydrofluoric acid as a shape controlling agent. Following this work, a series of studies extended this new route to synthesize more $\mathrm{TiO}_{2}$ sheets with exposed $\{001\}$ facets as candidates for photocatalysis applications [12,15-20]. However, the construction of hierarchical structures from these interesting anatase $\mathrm{TiO}_{2}$ nanosheets has not been realized. Hierarchically structured porous materials are of great interest to catalysis where an accurately controlled pore texture at different length scales can help reduce or control transport limitations [21-24]. Recent progress showed that the catalytic process can occur more efficiently in materials with a hierarchical pore size distribution on the nanoscale [21-25]. Thus, for use as a highly efficient photocatalyst, $\mathrm{TiO}_{2}$ hierarchical structure self-assembled from anatase $\mathrm{TiO}_{2}$ nanosheets with dominant $\{001\}$ facets is highly desirable. Chen et al. [26] reported the fabrication of hierarchical spheres self-assembled from ultrathin anatase $\mathrm{TiO}_{2}$ nanosheets with exposed $\{001\}$ facets using a nonaqueous synthetic route. However, these ultrathin anatase $\mathrm{TiO}_{2}$ nanosheets were stabilized by a surfactant (diethylenetriamine), and the crystal surface was highly passivated by this surfactant, which caused a rapid decrease in photocatalytic activity. Liu and co-workers [13] reported the synthesis of hierarchical flower-like $\mathrm{TiO}_{2}$ nanostructures with exposed $\{001\}$ facets by a hydrothermal method. However, the percentage of exposed $\{001\}$ facets was only about $10 \%-30 \%$.

In this work, we report a template- and surfactant-free alcohothermal route for the preparation of hierarchical flower-like $\mathrm{TiO}_{2}$ superstructures (HFTS) assembled from anatase $\mathrm{TiO}_{2}$ nanosheets with dominant $\{001\}$ facets.

\section{Experimental}

\subsection{Preparation of titanate nanotubes}

Titanate nanotubes were prepared by a hydrothermal method described in our previous work [27]. In a typical synthesis, $1.5 \mathrm{~g}$ of Degussa P25 powders was mixed with $140 \mathrm{ml}$ of $10 \mathrm{~mol} / \mathrm{L} \mathrm{NaOH}$ solution in a $200 \mathrm{ml}$ Teflon-lined autoclave. This was followed by the hydrothermal treatment of the mixture at $150{ }^{\circ} \mathrm{C}$ for $48 \mathrm{~h}$. After hydrothermal reaction, the precipitate was separated by filtration and washed with a $0.1 \mathrm{~mol} / \mathrm{L} \mathrm{HCl}$ aqueous solution and distilled water until the $\mathrm{pH}$ value of the rinsing solution reached 6.5 , which approached the $\mathrm{pH}$ value of the distilled water. The washed samples were dried in a vacuum oven at $80{ }^{\circ} \mathrm{C}$ for $8 \mathrm{~h}$.

\subsection{Synthesis of HFTS}

In a typical preparation procedure, $0.2 \mathrm{~g}$ of titanate nanotube powders prepared described above, $10 \mathrm{ml}$ of absolute ethanol, and $0.4 \mathrm{ml}$ of hydrofluoric acid solution (40\%) were mixed in a dry Teflon-lined autoclave with a capacity of $100 \mathrm{ml}$ at room temperature. This was then kept at $180{ }^{\circ} \mathrm{C}$ for $24 \mathrm{~h}$. After cooling to room temperature, the white precipitates were collected, washed with ethanol and distilled water three times, and then dried in an oven at $80{ }^{\circ} \mathrm{C}$ for $6 \mathrm{~h}$. For comparison, the samples were also prepared in pure water and in glycol, with all other experimental conditions kept the same.

\subsection{Characterization}

Morphological observations were performed on an S-4800 field emission scanning electron microscope (SEM, Hitachi, Japan) linked with an Oxford Instruments X-ray analysis system. Transmission electron microscopy (TEM) and high resolution transmission electron microscopy (HRTEM) analyses were conducted on a JEM-2100F electron microscope (JEOL, Japan) using a $200 \mathrm{kV}$ accelerating voltage. The X-ray diffraction (XRD) measurements, used to characterize the crystalline phase, phase composition, and crystallite size of the $\mathrm{TiO}_{2}$ powders, were carried out on an X-ray diffractometer (type HZG41B-PC) using $\mathrm{Cu} K_{\alpha}$ radiation at a scan rate of $0.05 \%$. The accelerating voltage and applied current were $40 \mathrm{kV}$ and $80 \mathrm{~mA}$, respectively. The Brunauer-Emmett-Teller (BET) specific surface area $\left(A_{\mathrm{BET}}\right)$ of the powders was measured by nitrogen adsorption in a 
Micromeritics ASAP 2020 nitrogen adsorption apparatus (USA). All the samples were degassed at $180{ }^{\circ} \mathrm{C}$ prior to nitrogen adsorption measurements. The BET surface area was determined by a multipoint BET method using the adsorption data in the relative pressure $\left(p / p_{0}\right)$ range of 0.05-0.3. A desorption isotherm was used to determine the pore size distribution by the Barret-Joyner-Halender (BJH) method, and assuming a cylindrical pore model [28]. The nitrogen adsorption volume at the relative pressure $\left(p / p_{0}\right)$ of 0.994 was used to determine the pore volume and average pore size. UV-Vis diffuse reflectance spectra of the powders were obtained from dry-pressed disk samples with a UV-Vis spectrometer (UV2550, Shimadzu, Japan). $\mathrm{BaSO}_{4}$ was used as a reflectance standard in the UV-Vis diffuse reflectance experiments.

\subsection{Measurements of photocatalytic activity}

The photocatalytic activity measurements of the $\mathrm{TiO}_{2}$ samples and P25 were performed according to reported procedures $[7,22,23]$. The mass of the photocatalyst used for each experiment was $0.1 \mathrm{~g}$. Analysis of acetone, carbon dioxide, and water vapor concentration was conducted online with a Photoacoustic IR Multigas Monitor (INNOVA Air Tech Instruments Model 1412). The initial concentration of acetone after adsorption equilibrium was $300 \pm 20$ ppm, which remained constant for about 5 min until a $15 \mathrm{~W}$, $365 \mathrm{~nm}$ UV lamp (4 cm above the dishes; Cole-Parmer Instrument Co., USA) in the reactor was switched on. The integrated UV intensity in the wavelength range of 310-400 $\mathrm{nm}$ striking the samples measured with a UV radiometer (UV-A, China) was $2.9 \mathrm{~mW} / \mathrm{cm}^{2}$. The peak wavelength of the UV light was $365 \mathrm{~nm}$. During the photocatalytic reaction, a nearly 3:1 ratio of carbon dioxide products to acetone destroyed was observed, and the acetone concentration decreased steadily with UV illumination time. Our previous and present experiments indicated that acetone was completely decomposed into $\mathrm{CO}_{2}$ and $\mathrm{H}_{2} \mathrm{O}$ and no other products were observed. Each set of experiment was followed for $60 \mathrm{~min}$.

The photocatalytic decolorization of methyl orange (MO) aqueous solution using HFTS was also conducted at ambient temperature using a procedure reported in our previous studies $[8,20]$. The experimental details were as follows. 0.1 g sample was dispersed into a $25 \mathrm{ml} \mathrm{MO}$ aqueous solution with a concentration of $4 \times 10^{-5} \mathrm{~mol} / \mathrm{L}$ in a $7.0 \mathrm{~cm}$ culture dish. A $15 \mathrm{~W}, 365 \mathrm{~nm}$ UV lamp (4 cm above the dishes; Cole-Parmer Instrument Co., USA) was used as light source. The concentration of MO was monitored by a UV-2550 UV-Vis spectrophotometer (Shimadzu, Japan).

\section{Results and discussion}

\subsection{Characterization results of the samples}

Figure 1 shows XRD pattern of HFTS prepared. The XRD pattern of the product synthesized was indexed to the anatase phase of $\mathrm{TiO}_{2}$ (JCPDS 21-1272; space group: $\mathrm{I}_{1} /$ amd (141)). The intense and sharp diffraction peaks indicated that the product had high purity and good crystallinity.

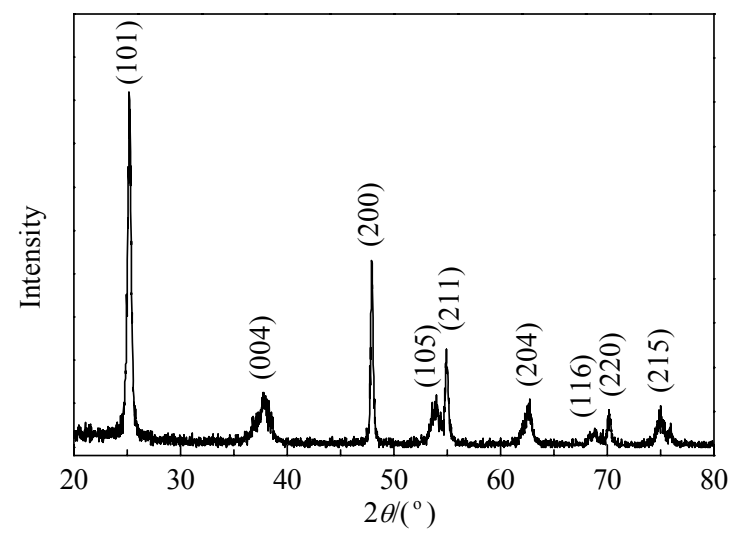

Fig. 1. XRD pattern of HFTS prepared.

The morphology and microstructure of the product were studied by SEM and TEM (Fig. 2). SEM image (Fig. 2(a)) of the $\mathrm{TiO}_{2}$ product showed that they consisted of flower-like $\mathrm{TiO}_{2}$ microspheres with diameters in the range of 1-2 $\mu \mathrm{m}$. High magnification SEM images (Fig. 2(b)) revealed that the flower-like $\mathrm{TiO}_{2}$ structure was produced from $\mathrm{TiO}_{2}$ nanosheets with side lengths of $300-400 \mathrm{~nm}$, and thicknesses of ca. $25 \mathrm{~nm}$. These nanosheets interconnect with each other to form a three dimensional structure having pores of different sizes, which can serve as transport paths for small molecules. The corresponding TEM image (Fig.
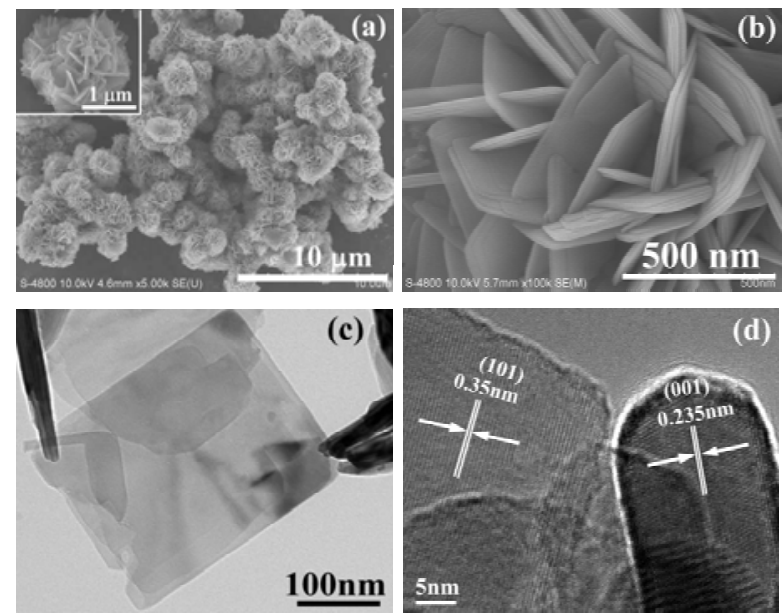

Fig. 2. SEM (a, b), TEM (c), and HRTEM (d) images of HFTS prepared. Inset in (a) is a magnified image of an individual spherical superstructure. 
2(c)) further confirmed that the flower-like $\mathrm{TiO}_{2}$ superstructure consisted of well defined sheet shaped structures having a rectangular form, with an average side size of 300-400 nm. The HRTEM image (Fig. 2(d)) directly showed that the lattice spacing parallel to the top and bottom facets was ca. $0.235 \mathrm{~nm}$, which corresponded to the (001) planes of anatase $\mathrm{TiO}_{2}$. This indicated the top and bottom facets of the nanosheets were the (001) and (00-1) planes, respectively. Another set of lattice fringes with the spacing of $0.35 \mathrm{~nm}$, which corresponded to the (101) planes of anatase, was also clearly revealed from the sheets lying on the TEM grid. On the basis of the above structural information, the percentage of the $\{001\}$ facets in the flower-like $\mathrm{TiO}_{2}$ superstructure was estimated to be $87 \%$ as calculated by a reported method [11].

The porous structure and texture of HFTS observed by SEM were further confirmed by $\mathrm{N}_{2}$ adsorption-desorption analysis. Figure 3 displays $\mathrm{N}_{2}$ adsorption-desorption isotherms and the corresponding pore size distribution curve for HFTS. HFTS gave type IV isotherms (Brunauer-Deming-Deming-Teller classification) $[21,28]$, which indicated the presence of mesopores $(2-50 \mathrm{~nm})$. The shapes of the hysteresis loops were of type $\mathrm{H} 3$, associated with textural larger pores due to the aggregation of nanosheets into the flower-like superstructures. This was consistent with the SEM images. The pore size distribution further confirmed that HFTS contained small mesopores (peak pore of $10 \mathrm{~nm}$ ) and large mesopores with a peak pore diameter of $40 \mathrm{~nm}$.
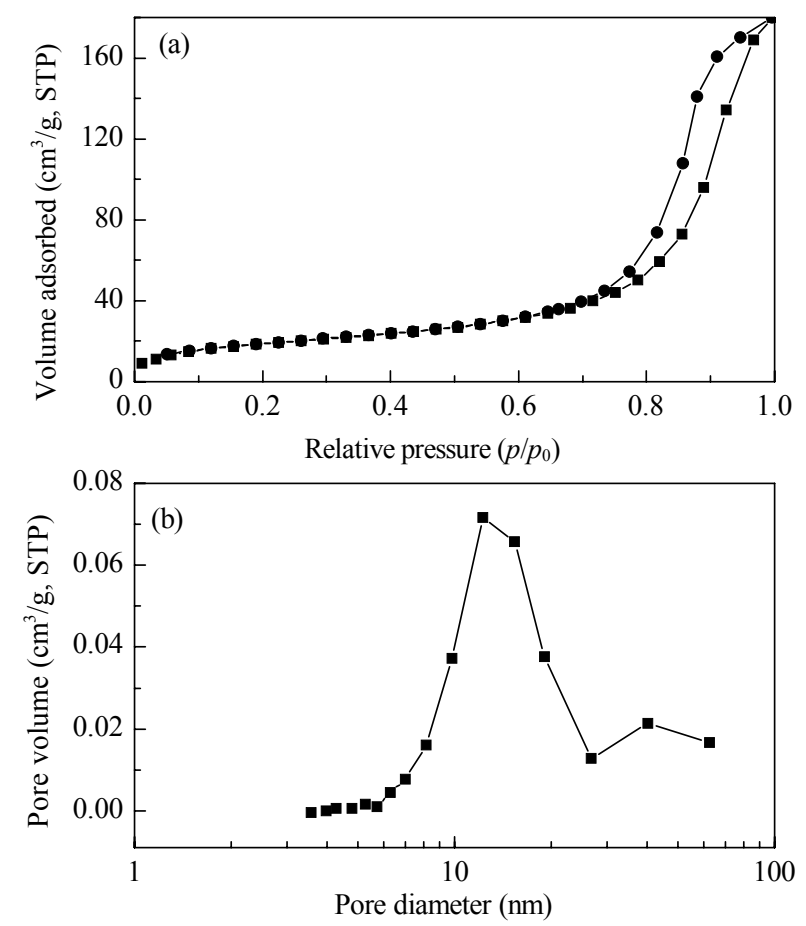

Fig. 3. Nitrogen adsorption-desorption isotherms (a) and the corresponding pore size distribution curve (b) of HFTS.
Information on macropores $(100-500 \mathrm{~nm})$ cannot be obtained by $\mathrm{N}_{2}$ adsorption-desorption analysis, but macroporous structures were clearly observed in the SEM images (Fig. 2(a) and 2(b)). Such hierarchically organized porous structures can be extremely useful in catalysis and photocatalysis as they can provide efficient transport pathways for reactant molecules to the interior void space.

It has been demonstrated that titanate nanotubes can be transformed into anatase $\mathrm{TiO}_{2}$ nanofibers by a hydrothermal method [29]. First principle calculations have indicated that fluorine ions can greatly reduce the surface energy of $\{001\}$ facets, making them more stable than the $\{101\}$ facets [11]. Therefore, hydrofluoric acid added into the solution played a key role in the isotropic growth along the [010] and [100] axes. Ethanol also played important roles in this synthetic system for the formation of HFTS. It acts as reaction medium and also as a protective capping agent to retard the growth of anatase $\mathrm{TiO}_{2}$ single crystals along the [001] direction. Further experiments were carried out to clarify the role of ethanol in the formation of HFTS. Figure 4(a) shows the SEM images of the sample prepared using pure water to replace absolute ethanol. Only tabular shape crystals were obtained and the XRD pattern (see Fig. 4(b)) indicated that the product was pure anatase $\mathrm{TiO}_{2}$. According to the structural information of a truncated bipyramid shape anatase single crystal, we estimate the percentage of exposed $\{001\}$
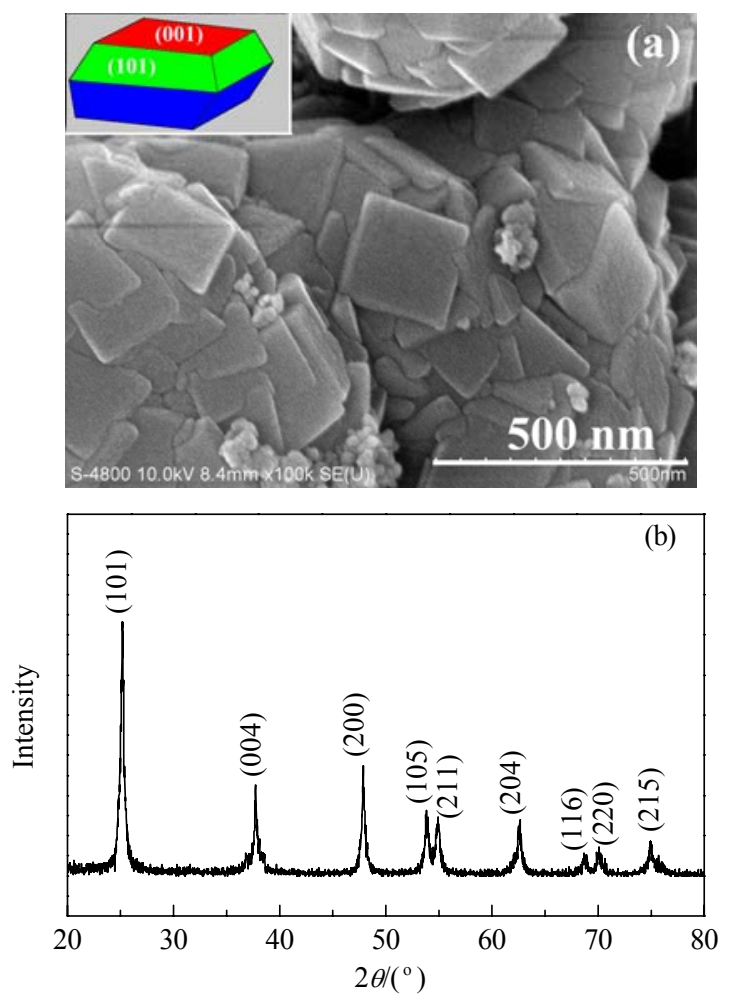

Fig. 4. SEM image (a) and XRD pattern (b) of tabular shaped $\mathrm{TiO}_{2}$ obtained using pure water. The inset in (a) shows a simulated shape of the anatase $\mathrm{TiO}_{2}$ single crystal. 
facets on the tabular shape crystal to be about $27 \%$. Moreover, when absolute ethanol was replaced by other alcohols such as glycol, only aggregated nanoparticles (not shown here) were obtained. This was due to the high viscosity of glycol which retarded the formation of HFTS. These observations confirmed that absolute ethanol strengthened the stabilization effect associated with fluorine adsorption on the (001) surface and thus stimulated its preferred growth, and maximized the exposure of $\{001\}$ facets. Therefore, we conclude that ethanol is particularly important in producing HFTS with dominant $\{001\}$ facets demonstrated in this synthesis system.

The formation mechanism of the flower-like $\mathrm{TiO}_{2}$ superstructure was investigated by SEM analysis of the structures isolated from the reaction mixture after various reaction times. Prior to reaction $(0 \mathrm{~h})$, the samples consisted of titanate nanotubes with diameters of 7-15 $\mathrm{nm}$ and lengths of several hundred nanometers (Fig. 5(a)). After reaction for 3 $\mathrm{h}$, the nanotubes were completely transformed into 10-20 $\mathrm{nm}$ nanoparticles (Fig. 5(b)). XRD analysis (not shown here) indicated that these nanoparticles were anatase $\mathrm{TiO}_{2}$. With further increase of the reaction time to $6 \mathrm{~h}$, many nanosheets with side length of $50 \mathrm{~nm}$ and thickness of 10 $\mathrm{nm}$ were observed (Fig. 5(c)). Figure 5(d) shows SEM image of the sample collected at $24 \mathrm{~h}$. It can be seen that the nanosheets with side length of 300-400 nm and thickness of $25 \mathrm{~nm}$ interconnect with each other to form a three dimensional structure. From the present results, it can be inferred that the formation of the flower-like $\mathrm{TiO}_{2}$ superstructure began with the appearance of large numbers of tiny nanoparticles from titanate nanotubes. Then, these nanoparticles undergo oriented attachment sideways to induce the formation of nanosheets with exposed (001) planes. Subsequently, the nanosheets were assembled at a higher level by lateral interactions, and the hierarchical $\mathrm{TiO}_{2}$ flower-like microstructure was formed.

The above results highlighted a facile alcohothermal strategy for the synthesis of hierarchical flower-like trimodal macro-/mesoporous superstructures in the absence of templates and additives. The $\mathrm{TiO}_{2}$ powders prepared are composed of at least three levels of structural organization: (i) $\mathrm{TiO}_{2}$ crystallization at the nanoscale (nanosheets), (ii) mesoscale aggregation and packing of the $\mathrm{TiO}_{2}$ nanosheets (several to several tens nanometers) to produce bimodal peak mesopores located at 10 and $40 \mathrm{~nm}$, and (iii) flower-like microspheres with a macroporous framework at the micrometer scale [23].

\subsection{Photocatalytic activity of the samples}

The photocatalytic activity of HFTS was evaluated by the photocatalytic oxidation decomposition of acetone in air under UV light illumination. For comparison, the photocatalytic activities of a commercial $\mathrm{TiO}_{2}$ powder Degussa P25 and the tabular shaped $\mathrm{TiO}_{2}$ particles (TSTP) prepared (shown in Fig. 4) were also measured at the same conditions. Figure 6 shows the plots of $\ln \left(C_{t} / C_{0}\right)$ versus irradiation time $\left(C_{t}\right.$ and $C_{0}$ denote the reaction and initial concentrations of acetone, respectively). The photocatalytic activity of TSTP was relatively low, probably due to a smaller specific area $\left(9.7 \mathrm{~m}^{2} / \mathrm{g}\right.$, see Table 1$)$. In contrast, HFTS showed higher photocatalytic activity than TSTP and P25. It should be noted that the latter is well known for its superior photocatalytic activity. The enhanced photocatalytic activity of HFTS can be explained by the inter-meshed nanosheets, hierarchical porous structures, and exposed $\{001\}$ facets. As schematically illustrated in the inset of Fig. 6(a), the inter-meshed nanosheets provide for multiple reflections of
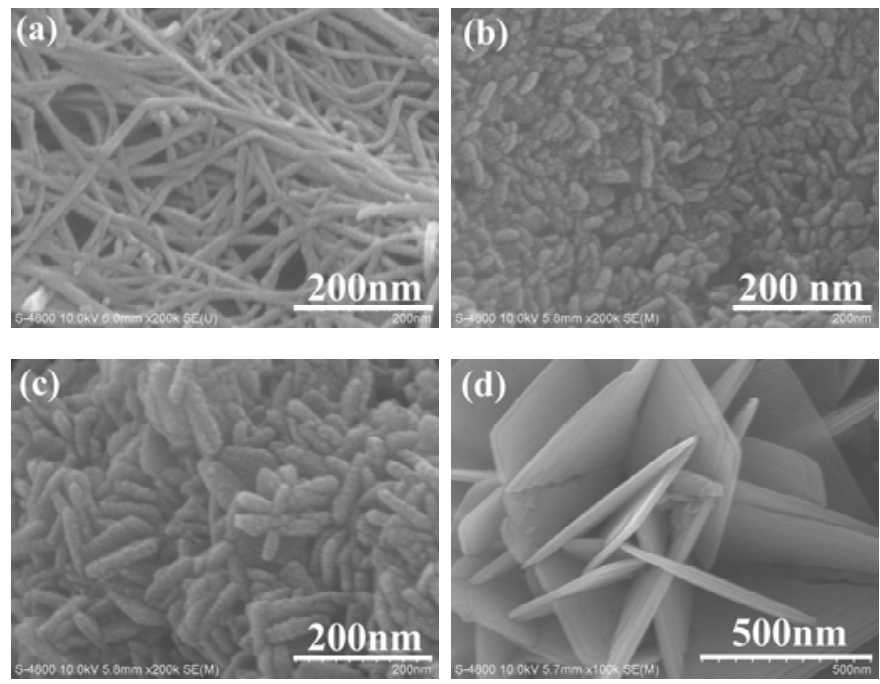

Fig. 5. SEM images of the products obtained at different reaction times: (a) 0, (b) 3, (c) 6, and (d) $24 \mathrm{~h}$. 


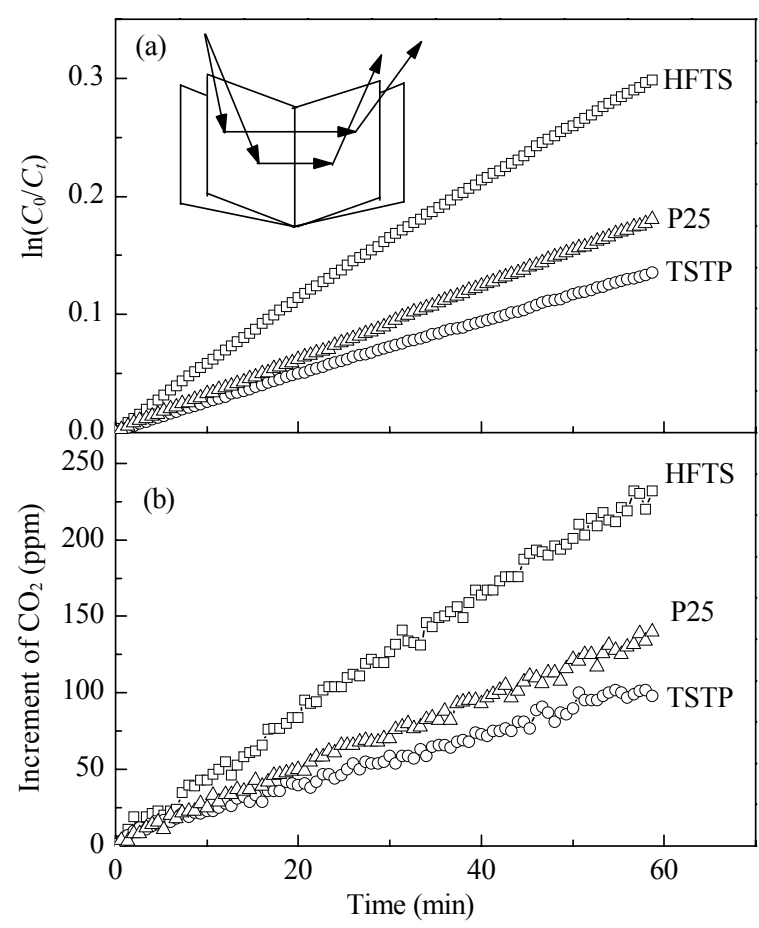

Fig. 6. (a) Comparison of the photocatalytic activity of HFTS, TSTP, and P25 for photocatalytic decomposition of acetone in air. (b) Dependence of produced $\mathrm{CO}_{2}$ concentration on irradiation time for HFTS, TSTP, and P25. The inset in (a) shows a schematic illustration of multireflections within the inter-meshed nanosheets.

UV light, which enhanced light harvesting and increased the quantities of photogenerated electrons and holes that participate in photocatalytic reactions [30,31]. This was also confirmed by the UV-Vis absorption spectra of HFTS (see Fig. 7), which clearly indicated that HFTS has a stronger absorbance in the UV region than the tabular shaped $\mathrm{TiO}_{2}$ particles. Furthermore, the hierarchical porous structure was also beneficial in enhancing the flow and transfer rate of reactant and products molecules [22,23]. Finally, theoretical and experimental studies have indicated that the (001) surface of anatase $\mathrm{TiO}_{2}$ is much more reactive than the thermodynamically more stable (101) surface because of its special electronic and surface structures [11,32,33]. One possible explanation for why the $\{001\}$ facets of $\mathrm{TiO}_{2}$ nanosheets enhanced photocatalytic activity is seen on comparing it with $\mathrm{TiO}_{2}$ nanoparticles. The $2 \mathrm{D}$ nanosheets with exposed $\{001\}$ facets can more easily enhance the adsorption of pollutant molecules due to its highly reactive

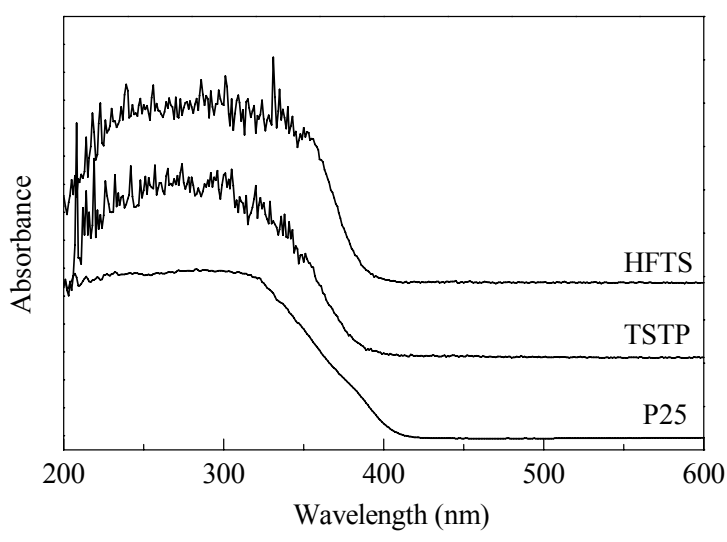

Fig. 7. UV-Vis spectra of HFTS, TSTP, and P25.

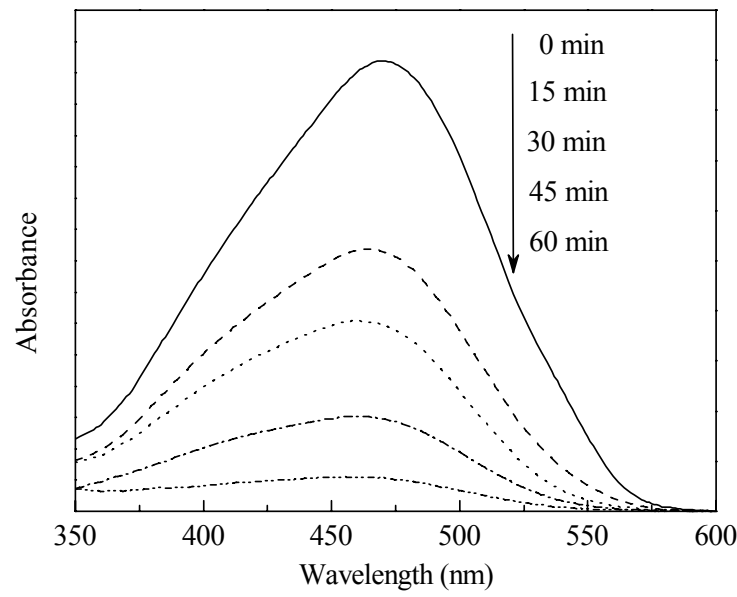

Fig. 8. UV-Vis spectra of MO aqueous solution at ambient temperature in the presence of HFTS under UV light irradiation.

surface, which would lead to the enhancement of photocatalytic activity [13,33-35]. Therefore, it is not surprising that the photocatalytic efficiency of HFTS was much better.

In addition, HFTS was also used to perform the photocatalytic degradation of MO aqueous solution to further demonstrate its potential environmental application for the removal of contaminants from wastewater. As shown in Fig. 8 , it also showed high photocatalytic efficiency for the degradation of $\mathrm{MO}$ in aqueous solution, and more than $95 \%$ of MO was degraded within $60 \mathrm{~min}$. This further confirmed the high photocatalytic activity of HFTS.

Additional experiments showed that HFTS was more readily separated and can be reused from the slurry system by filtration or sedimentation after photocatalytic reaction

Table 1 Physicochemical properties of HFTS, TSTP, and P25

\begin{tabular}{lcccccc}
\hline Sample & Phase & $A_{\mathrm{BET}} /\left(\mathrm{m}^{2} / \mathrm{g}\right)$ & Average pore size $(\mathrm{nm})$ & Pore volume $\left(\mathrm{cm}^{3} / \mathrm{g}\right)$ & Porosity $(\%)$ & Percentage of $\{001\}(\%)$ \\
\hline HFTS & anatase & 38.9 & 11.7 & 0.28 & 50.9 & $87 \pm 5$ \\
TSTP & anatase & 9.7 & 46.5 & 0.11 & 28.9 & $27 \pm 5$ \\
P25 & anatase + rutile & 55.1 & 3.9 & 0.06 & 18.2 & - \\
\hline
\end{tabular}


than nano-sized powder photocatalytic materials due to their large weight and weak Brownian motion. Therefore, the HFTS prepared can be regarded as a better photocatalyst for environmental purification at the industrial scale. This is the first report of the preparation and photocatalytic activity of HFTS self-assembled from anatase $\mathrm{TiO}_{2}$ nanosheets with dominant $\{001\}$ facets (up to $87 \%$ ).

\section{Conclusions}

Hierarchical flower-like $\mathrm{TiO}_{2}$ superstructures self-assembled from anatase $\mathrm{TiO}_{2}$ nanosheets with exposed $\{001\}$ facets were successfully prepared by a simple template- and surfactant-free alcohothermal method with the assistance of hydrofluoric acid. The photocatalytic activity of HFTS was higher than that of P25 and tubular shaped anatase $\mathrm{TiO}_{2}$ obtained using pure water as the synthesis medium. This was due to the synergetic effects of two factors: (i) hierarchical porous structure and intense UV light absorption, and (ii) exposure of highly reactive $\{001\}$ facets of the nanosheets. The former means that more photogenerated electrons and holes are produced, thus enhancing photocatalytic activity. The latter was due to the fact that the $2 \mathrm{D}$ nanosheets with exposed $\{001\}$ facets enhanced the adsorption of pollutant molecules due to its highly reactive surface. Further results showed that HFTS can be more readily separated and reused from the slurry system after photocatalytic reaction than nano-sized powder photocatalytic materials. This study provided new physical chemical insight into the enhancement mechanism of photocatalytic activity and further enhanced our understanding of the relationship between morphology and activity of $\mathrm{TiO}_{2}$. The HFTS is also of interest for the development of solar cells, optoelectronic devices, sensors, and catalysts.

\section{References}

1 Park J H, Kim S, Bard A J. Nano Lett, 2006, 6: 24

2 Hoffmann M R, Martin S T, Choi W, Bahnemann D W. Chem Rev, 2002, 95: 69

3 Ksibi M, Rossignol S, Tatibouet J M, Trapalis C. Mater Lett, 2008, 62: 4204

4 Li Y X, Lu G X, Li S B. J Photochem Photobiol A, 2002, 152: 219

5 Cheng Y W, Chan R C Y, Wong P K. Water Res, 2007, 41: 842

6 Liu G, Wang L Z, Yang H G, Cheng H M, Lu G Q. J Mater Chem, 2010, 20: 831
7 Yu J C, Yu J G, Ho W K, Jiang Z T, Zhang L Z. Chem Mater, 2002, 14: 3808

8 Xiang Q J, Yu J G, Cheng B, Ong H C. Chem Asian J, 2010, 5: 1466

9 Gong X Q, Selloni A. J Phys Chem B, 2005, 109: 19560

10 Selloni A. Nat Mater, 2008, 7: 613

11 Yang H G, Sun C H, Qiao S Z, Zou J, Liu G, Smith S C, Cheng H M, Lu G Q. Nature, 2008, 453: 638

12 Han X G, Kuang Q, Jin M S, Xie Z X, Zheng L S. J Am Chem Soc, 2009, 131: 3152

13 Liu M, Piao L Y, Lu W M, Ju S T, Zhao L, Zhou C L, Li H L, Wang W J. Nanoscale, 2010, 2: 1115

14 Diebold U. Surf Sci Rep, 2003, 48: 53

15 Yang H G, Liu G, Qiao S Z, Sun C H, Jin Y G, Smith S C, Zou J, Cheng H M, Lu G Q. J Am Chem Soc, 2009, 131: 4078

16 Liu G, Sun C H, Yang H G, Smith S C, Wang L Z, Lu G Q, Cheng H M. Chem Commun, 2010, 46: 755

17 Wu B H, Guo C Y, Zheng N F, Xie Z X, Stucky G D. J Am Chem Soc, 2008, 130: 17563

18 Amano F, Prieto-Mahaney O O, Terada Y, Yasumoto T, Shibayama T, Ohtani B. Chem Mater, 2009, 21: 2601

19 Alivov Y, Fan Z Y. J Phys Chem C, 2009, 113: 12954

20 Yu J G, Xiang Q J, Ran J R, Mann S. CrystEngComm, 2010, 12: 872

21 Yu J G, Yu H G, Guo H T, Li M, Mann S. Small, 2008, 4: 87

22 Yu J G, Su Y R, Cheng B. Adv Funct Mater, 2007, 17: 1984

23 Yu J G, Zhang L J, Cheng B, Su Y R. J Phys Chem C, 2007, 111: 10582

24 Collins A, Carriazo D, Davis S A, Mann S. Chem Commun, 2004: 568

25 Coppens M O, Sun J, Maschmeyer T. Catal Today, 2001, 69: 331

26 Chen J S, Tan Y L, Li C M, Cheah Y L, Luan D, Madhavi S, Boey F Y C, Archer L A, Lou X Y. J Am Chem Soc, 2010, 132: 6124

27 Yu J G, Xiang Q J, Zhou M H. Appl Catal B, 2009, 90: 595

28 Sing K S W, Everett D H, Haul R A W, Moscou L, Pierotti R A, Rouquerol J, Siemieniewska T. Pure Appl Chem, 1985, 57: 603

29 Yu J G, Yu H G, Cheng B, Zhao X J, Zhang Q. J Photochem Photobiol A, 2006, 182: 121

30 Yu X X, Yu J G, Cheng B, Jaroniec M. J Phys Chem C, 2009, 113: 17527

31 Jiang $\mathrm{P}$, Zhou J J, Fang H F, Wang C Y, Wang Z L, Xie S S. Adv Funct Mater, 2007, 17: 1303

32 Xiang Q J, Lv K L, Yu J G. Appl Catal B, 2010, 96: 557

33 Liu S W, Yu J G, Jaroniec M. J Am Chem Soc, 2010, 132: 11914

34 Yu J G, Fan J J, Lv K L. Nanoscale, 2010, 2: 2144

35 Yu J G, Qi L F, Jaroniec M. J Phys Chem C, 2010, 114: 13118 